\title{
Transfer of Satellite Rainfall Uncertainty from Gauged to Ungauged Regions at Regional and Seasonal Timescales
}

Ling Tang and Faisal Hossain

Science Systems and Applications, Inc.

NASA Goddard Space Flight Center, Laboratory for Atmospheres Greenbelt, MD 20771, USA

\author{
Submitted to: \\ Journal of Hydrometeorology \\ Revised: July 7, 2010 \\ Corresponding Author \\ Dr. Faisal Hossain \\ Department of Civil and Environmental Engineering \\ Tennessee Technological University \\ 1020 Stadium Drive, Box 5015 \\ Cookeville, TN 38505 \\ USA
}


ABSTRACT

36 Hydrologists and other users need to know the uncertainty of the satellite rainfall data sets across

37 the range of time/space scales over the whole domain of the data set. Here, 'uncertainty' refers to

38 the general concept of the 'deviation' of an estimate from the reference (or ground truth) where

39 the deviation may be defined in multiple ways. This uncertainty information can provide insight

40 to the user on the realistic limits of utility, such as hydrologic predictability, that can be achieved

41 with these satellite rainfall data sets. However, satellite rainfall uncertainty estimation requires

42 ground validation (GV) precipitation data. On the other hand, satellite data will be most useful

43 over regions that lack GV data, for example developing countries. This paper addresses the open

44 issues for developing an appropriate uncertainty transfer scheme that can routinely estimate

45 various uncertainty metrics across the globe by leveraging a combination of spatially-dense GV

46 data and temporally sparse surrogate (or proxy) GV data, such as the Tropical Rainfall

47 Measuring Mission (TRMM) Precipitation Radar and the Global Precipitation Measurement

48 (GPM) mission Dual-Frequency Precipitation Radar. The TRMM Multi-satellite Precipitation

49 Analysis (TMPA) products over the US spanning a record of 6 years are used as a representative

50 example of satellite rainfall. It is shown that there exists a quantifiable spatial structure in the

51 uncertainty of satellite data for spatial interpolation. Probabilistic analysis of sampling offered by

52 the existing constellation of passive microwave sensors indicate that transfer of uncertainty for

53 hydrologic applications may be effective at daily time scales or higher during the GPM era.

54 Finally, a commonly used spatial interpolation technique (kriging), that leverages the spatial

55 correlation of estimation uncertainty, is assessed at climatologic, seasonal, monthly and weekly

56 timescales. It is found that the effectiveness of kriging is sensitive to the type of uncertainty

57 metric, time scale of transfer and the density of GV data within the transfer domain. Transfer

58 accuracy is lowest at weekly timescales with the error doubling from monthly to weekly. 
59 However, at very low GV data density ( $<20 \%$ of the domain), the transfer accuracy is too low to

60 show any distinction as a function of the timescale of transfer.

61

62 Keywords: Satellite precipitation, uncertainty, transfer, spatial interpolation, GPM.

63 


\subsection{INTRODUCTION}

Precipitation is arguably one of the most important components of the water cycle over

66 land. One study shows that almost $70-80 \%$ of the variability in the terrestrial water cycle can be

67 explained from the spatio-temporal variability observed in precipitation over land (Syed et al.,

68 2004). Existing missions such as the Tropical Rainfall Measurement Mission (TRMM) provide

69 vital precipitation information for water cycle studies (Huffman et al., 2007). Furthermore,

70 planned missions such as the Global Precipitation Measurement (GPM) mission will provide a

71 global hydrologic remote sensing observatory to advance the use of precipitation sensing

72 technologies in scientific inquiry into hydrologic processes (Krajewski et al., 2006). With the

73 global and more frequent precipitation observational capability planned for GPM, such

74 precipitation measuring satellite missions permit us to refine knowledge from physical and

75 hydrologic models that can then be converted to local and global strategies for water resources

76 management (Voisin et al., 2008; Hossain et al., 2007). [Hereafter, because our focus is on

77 liquid precipitation, the term 'rainfall' will be used as shorthand for 'precipitation' for

78 convenience]

79 However, a crucial challenge in advancing satellite rainfall-based surface hydrologic

80 prediction, is the need to bridge the scale incongruity between overland hydrologic processes that

81 evolve at small scales (i.e., $<1$ hour and $<5 \mathrm{~km}$ ) and operational satellite precipitation datasets

82 that will always be restricted to coarser scales from passive microwave sensors (i.e., $>1$ hour and

$83>5 \mathrm{~km}$; Hossain and Lettenmaier, 2006). There are two paths that have historically been

84 followed as a response to this scale incongruity: 1) apply satellite rainfall data available at the

85 native scale for hydrologic prediction (e.g., Harris and Hossain, 2008; Su et al., 2008; Voisin et

86 al., 2008); and 2) apply spatial and spatio-temporal disaggregation (or downscaling) techniques 
87 to resolve satellite rainfall data at the required smaller space-time scales for hydrologic 88 prediction (e.g., Forman et al., 2009; Bindlish and Barros, 2000). Each option leads to non89 negligible uncertainty in hydrologic simulation. In the first case, the major source of this 90 uncertainty is due to the algorithmic and sampling uncertainty (for passive microwave-PMW 91 sensors) of satellite rainfall data at the native scale. In the second case, the primary source of 92 uncertainty is due to the statistical disaggregation technique that further propagates the native 93 scale uncertainty to sub-grid uncertainty in ways that are not well understood (see for example,

94 Rahman et al., 2009). Either way, hydrologists and other users, need to know the uncertainty of 95 the satellite rainfall data sets across the range of time/space scales over the whole domain of the 96 data set. This uncertainty can provide insightful information to the user on the realistic limits of 97 utility that can be achieved with satellite rainfall data sets, for example for hydrologic 98 predictability (Hong et al., 2006), on which we will focus in this paper. While representing the 99 uncertainty structure of satellite rainfall as a function of scale against quality-controlled ground 100 validation datasets remains a critical research problem for GPM, therein lies a paradox. Satellite 101 rainfall uncertainty estimation requires ground validation $(\mathrm{GV})$ precipitation data. On the other 102 hand, satellite data will be most useful over ungauged regions in the developing world (Tang and 103 Hossain, 2009).

104 In-situ rainfall information from rain gauge networks is generally considered the standard 105 choice for GV data (Villarini and Krajewski, 2007; Habib et al., 2004; McCollum et al., 2002). 106 Such data is often referred to as 'reference' or 'truth'. However, in-situ gauges are point 107 measurements and unless there exists a dense network to adequately capture the space-time 108 variability of rainfall process, its use for validating areal-averaged satellite rainfall data for 109 surface hydrologic processes remains questionable (Ciach and Krajewski, 1999). The work of 
110 Gebremichael et al. (2003) clearly demonstrates the sensitivity of satellite rainfall uncertainty

111 estimation to gauge density. Thus, in most regions across the globe without adequate $i n-s i t u$ rain

112 gauge coverage, the uncertainty associated with satellite data have been parameterized to

113 sampling configuration of the sensors at this stage (Li et al., 1998; Huffman, 1997). Some

114 examples of this parameterization are the Global Precipitation Climatology Project (GPCP;

115 Huffman, 2005; Huffman et al., 1997) dataset and the TRMM Multi-satellite Precipitation

116 Algorithm (TMPA; Huffman et al., 2007) that now provide an estimate of the Root Mean-

117 Squared Uncertainty (RMSE) of the satellite rainfall estimates on the basis of sampling pattern

118 and the period of rainfall accumulation of interest to the user.

119 While such parameterized methodologies for estimating uncertainty have been useful in

120 providing users with a level of confidence associated with satellite rainfall estimates, such

121 uncertainty is essentially a standard deviation measure of sampling uncertainty. Many of these

122 uncertainty methodologies are based on the conceptual argument that uncertainty (i.e, standard

123 deviation, $\left.\sigma_{\mathrm{E}}\right)$ can be related directly or inversely to observation interval $(\Delta \mathrm{t})$, observation period

$124(\mathrm{~T})$, spatial averaging area $(\mathrm{A})$, and rain rate $(\mathrm{R})$ :

125

126

$$
\sigma_{E}=f\left(\frac{1}{R}, \frac{1}{\mathrm{~A}}, \frac{\Delta \mathrm{t}}{\mathrm{T}}, \text { parameters }\right)
$$

128 as expressed by Steiner et al. (2003), among others. In many cases, the functional form of this 129 'predicted' uncertainty is not benchmarked to the realities of the ground observations and hence 130 may not provide a reasonable assessment in indicating the expected reliability for water cycle 131 studies (Gebremichael et al., 2010). Recently, several other parameterized methodologies have 132 evolved based on data assimilation approaches (e.g. Kalman filtering in GsMAP satellite product 
133 of Ushio et al., 2009). In these approaches, an estimate of uncertainty that is available is

134 essentially related to the methodology of the filtering technique and does not necessarily indicate

135 the actual level of agreement with GV rainfall data. In some instances, however, the uncertainty

136 is estimated by comparing the output of a wide-coverage technique (such as infrared-IR advected

137 PMW) to a more localised but higher accuracy product (such as PMW only; Ushio et al., 2009).

138 There now exists a sufficient body of knowledge on uncertainty metrics and models that

139 we should consider a transition to a more hydrologically-relevant framework in anticipation of

140 the satellite data-rich scenario of GPM. Although existing uncertainty metrics and uncertainty

141 models represent an important first step, most treat uncertainty as a single measure representative

142 for a large space and time domain. This uni-dimensional uncertainty measure is invariably the

143 standard deviation of uncertainty (e.g. Eqn. 1). However, a satellite rainfall product with an

144 uncertainty standard deviation $\left(\sigma_{\mathrm{E}}\right)$ of $\mathrm{X} \mathrm{mm} / \mathrm{hr}$ over a large space-time domain can be

145 represented by a multiplicity of distinct spatio-temporal patterns of rainfall, each having a

146 distinct response in surface hydrology (see for example, Lee and Anagnostou, 2004).

147 What is therefore needed now for advancing the hydrological application of GPM is a 148 practical methodology that can routinely 'transfer' a set of hydrologically-relevant uncertainty

149 metrics from locations/regions having GV-based values to ungauged regions for improving water 150 cycle studies or water resources management. Here, 'transfer' is akin to spatial interpolation at 151 non-sampled locations (grid boxes) using measurements from sampled but sparse locations (grid

152 boxes). Figure 1 provides a conceptual rendition of this idea of 'transfer' of uncertainty based on 153 the concept of spatial interpolation (taken from Ling and Hossain, 2009).

154 This paper analyzes the open issues for developing an appropriate uncertainty transfer 155 scheme that can routinely estimate various uncertainty metrics across the globe by leveraging a 
156 combination of spatially-dense GV data and temporally sparse surrogate (or proxy) GV data

157 from sources such as the TRMM-like PR sensor anticipated during the GPM era. The TRMM

158 Multi-satellite Precipitation Analysis (TMPA) products 3B42RT and 3B41RT (Huffman et al.,

159 2007) over the US spanning a record of 6 years are used as a representative example of satellite

160 rainfall. The paper presents a probabilistic analysis of sampling offered by the existing

161 constellation of precipitation-relevant satellite PMW sensors in order to understand the current

162 and expected spatial coverage during the GPM era. A commonly used spatial interpolation

163 technique (kriging), that leverages the spatial correlation of rainfall estimation uncertainty, is

164 then investigated for its effectiveness. This effectiveness is cast in the context of the expected

165 sparseness in GV data expected from TRMM and GPM missions. Finally, important issues

166 needing closure are summarized on the basis of our investigation of transfer of satellite rainfall

167 uncertainty from GV to non-GV regions. To avoid confusion among readers, hereafter, the terms

168 'uncertainty' or 'uncertainty metric' will be used to define the quality indices of the satellite

169 rainfall estimate derived at GV locations (such as bias, root mean squared error, probability of

170 detection). The terms 'error' or 'transfer error' will be used specifically to define the quality of

171 the transfer (spatial interpolation) process of uncertainty metrics at non-GV locations.

172

\subsection{SPATIAL CORRELATION OF SATELLITE RAINFALL UNCERTAINTY}

The very first requirement for an effective transfer (spatial interpolation) scheme is the

175 presence of a quantifiable spatial structure (or spatial correlation) in the variable being

176 transferred. Therefore, we first investigated the presence of spatial correlation of satellite rainfall

177 uncertainty. First, in order to minimize the error of the GV rainfall data, we used the National

178 Center for Environmental Prediction's (NCEP) $4 \mathrm{~km}$ Stage IV NEXRAD rainfall data that is

179 adjusted to precipitation gages and conveniently available as a quality-controlled data mosaic 
180 over the U.S. (Lin and Mitchell, 2005; Fulton et al., 1998). TMPA's near real-time satellite 181 rainfall data-products from PMW-calibrated Infrared (IR) and merged PMW-IR estimates 182 (labeled 3B41RT and 3B42RT, respectively; Huffman et al., 2007) were used as the satellite 183 rainfall data. The data for GV and satellite rainfall data spanned 6 years from 2002 to 2007. The 184 NEXRAD Stage IV GV rainfall data were first remapped to $0.25^{\circ}$ 3-hourly resolution for 185 consistency with the native scale of the satellite rainfall products. 3B41RT data were also 186 remapped at the 3-hourly time scale. After a thorough quality assessment and quality control 187 (QA/QC), the datasets were organized by season and various regions for the years 2002-2007.

188 In order to study how the satellite rainfall uncertainty is spatially dependent (or 189 correlated), Tang and Hossain (2009) derived the spatial correlograms for each uncertainty 190 metric using the TMPA dataset described above. Herein, the correlation length (CL), where the 191 autocorrelation dropped to 1/e (e-folding distance), was first computed. Next, the empirical semi192 variograms were derived and then idealized as exponential semi-variogram functions,

$$
\gamma(h)=c_{0}+c\left(1-e^{-h / a}\right)
$$

194 where $\gamma(h)$ is the semi-variance at spatial lag ' $h$ ', $\mathrm{c}_{0}$ represents the nugget variance (i.e., the 195 minimum variability observed or the 'noise' level at a separation distance of 0 ); $\mathrm{c}$ is the sill 196 variance (when spatial lag is infinite); and a is the correlation length. Figure 2 provides a 197 summary of the 'climatologic' correlation length (e-folding distance) by season for various 198 uncertainty metrics of the satellite rainfall products such as Probability of Detection (POD) for 199 rain, POD for no rain, false alarm ratio (FAR), root mean squared error (RMSE), and bias. 200 Herein, 'climatologic' refers to the mean error derived from the entire 6 year of data. Appendix 201 one provides the mathematical formulation for the error metrics. 
Figure 2 clearly demonstrates that, at the climatologic (long-term) time scale, satellite

203 rainfall uncertainty can have distinct spatial organization that can be leveraged for spatial

204 interpolation. The correlation lengths for a given uncertainty metric as a function of season

205 appear to be at least $3-5\left(0.25^{\circ}\right) \mathrm{TMPA}$ grid boxes long. As a rule of thumb, this indicates that

206 the transfer of error from sampled locations may be effective up to 4 grid boxes $(\sim 100 \mathrm{~km})$

207 away. Another interesting feature that is revealed in this figure is the significantly higher

208 correlation lengths (and spatial organization) observed for 3B41RT than 3B42RT. This can be

209 traced to the sources of the specific satellite estimates: 3B41RT is uniformly computed using a

210 calibration of infrared (IR) brightness temperatures to a combined PMW estimate. The statistics

211 of the uncertainty are spatially very homogenous since they originate from a single probability

212 distribution at regional scales. On the other hand, 3B42RT uses a variety of PMW rainfall

213 estimates with gaps filled during a 3-hour sampling period with the 3B41RT estimate 'as is'.

214 This fill-in causes the 3B42RT data to draw on two different probability distributions in space

215 for uncertainty statistics (IR and PMW); the increased spatial heterogeneity in the uncertainty

216 structure leads to shorter correlation length. This analysis shows that any uncertainty transfer

217 scheme should benefit from improvements in the 3B42RT product to make it statistically more

218 homogenous in space.

\subsection{SPATIAL COVERAGE OFFERED BY CURRENT CONSTELLATION OF PMW SENSORS}

224 the space/time dimension that is implicit in the concept of real-time uncertainty 'transfer' over

225 non-GV regions. The space dimension pertains to the regions with spatially sparse GV data due

226 to inadequate in-situ gauge data (such as that shown in Figure 1), which are, of course, recorded 
227 at fixed positions. The time dimension pertains to the temporally sparse case of using the most 228 accurate rainfall source currently available from space, such as the orbiting TRMM PR as 229 'proxy'-GV data, over regions where there is no ground-based GV data. Depending on how we 230 define GV data, there can be several types of GV 'voids' where uncertainty information will be 231 need to be estimated for GPM. For example, if we rely on the 'conventional' ground source for $232 \mathrm{GV}$ data, voids will be represented by large and stationary regions having little or no 233 instrumentation. On the other hand, if a 'proxy' for GV is defined from orbiting sensors, such as 234 the TRMM PR, or even a highly accurate PMW sensor, then voids will be numerous grid boxes 235 dynamically changing in location with each satellite orbit.

236 The left panel of Figure 3 shows the probability of a 3B42RT grid box $\left(0.25^{\circ}\right)$ having a 237 conical-scanning PMW overpass (comprising either TMI, SSMI or AMSR) in 3, 6 and 24 hour 238 windows. On the right panels of Figure 3, the probability of a 3B42RT grid box having a TRMM 239 Microwave Imager (TMI) scan is shown. These probability maps were created using a 100 day 240 period of any PMW sensor) from the 2007- 2008 period. It is clear from the maps that the spatio241 temporal dynamics of the location of PMW scans is strongly sensitive to the accumulation 242 periods of hydrologic relevance and one that must be investigated carefully in order to identify 243 how an uncertainty transfer scheme may work using proxy-GV data.

244 At time scales of 3-6 hours, there are vast regions lacking conventional surface GV data 245 in the tropics of Africa, Asia and South America where the probability of having a PMW scan is 246 less than $50 \%$ (Figure 3). This makes the estimation of uncertainty through transfer from GV 247 regions at these locations more important for hydrologic applications. While GPM may improve 248 the coverage of PMW scans, such large voids with a low probability for a PMW scan will still 249 remain over these regions due the continued dependence on polar-orbiting sensors. Since gauge- 
250 based GV is sparse for these tropical regions at hydrologic scales, proxy GV data from space-

251 borne sensors (such as that expected from the GPM Dual Frequency Precipitation Radar) may be

252 one of the few ways to explore if 'transfer' of uncertainty is realistic. For the higher latitude land

253 regions (which comprise mostly the industrialized world with reasonably gauged fixed-location

254 GV instrumentation), the uncertainty could be transferred from the stationary GV regions. The

255 right panels of Figure 3 also show that the probability of having a TMI scan also happens to be 256 lowest (0.1-0.2 in 3 hours) over the tropical regions. However, over a 24 hour time period there 257 is considerably higher probability of having such a scan $(\sim 0.7-0.8)$. This implies that the 258 practicable timescale for transferring uncertainty metrics over the tropics from a sun259 asynchronous PMW sensor is at least 24 hours.

\subsection{TRANSFER OF UNCERTAINTY BY SPATIAL INTERPOLATION}

Tang and Hossain (2009) recently showed that most uncertainty metrics (such as bias and

263 POD) are amenable to 'transfer' from gauged to ungauged locations using spatial interpolation at

264 climatologic (six-year average) timescales. The method of ordinary kriging (OK) was used for

265 testing the 'transfer' of uncertainty metrics. OK is the most common (and one of the simplest)

266 spatial interpolation estimator used to find the best linear unbiased estimate of a second-order

267 stationary random field with an unknown constant mean as follows:

268

$$
\hat{Z}\left(x_{0}\right)=\sum_{i=1}^{n} \lambda_{i} Z\left(x_{i}\right)
$$

269 where $\hat{Z}\left(x_{0}\right)=$ kriging estimate at location $\mathrm{x}_{0} ; Z\left(\mathrm{x}_{i}\right)=$ sampled value at location $\mathrm{x}_{i} ; \lambda_{\mathrm{i}}=$

270 weighting factor for $Z\left(\mathrm{x}_{i}\right)$ (summing to one over all $\mathrm{i}$ ), and $\mathrm{n}$ is the number of sampled (known)

271 locations. Kriging methods have already been used for spatial interpolation of precipitation from 272 point gauge data with considerable success (see for example, Seo et al., 1990; Krajewski, 1987). 
274 over the central US, the OK method was applied to assess the effectiveness of transfer of 275 uncertainty metrics from GV to non-GV grid boxes, using correlation as the main assessment 276 metric. Assuming that only $50 \%$ of the region (i.e., grid boxes) was gauged (i.e., having access to 277 GV data), OK was implemented to estimate uncertainty metrics at the other 50\% of the (non$278 \mathrm{GV}$ ) region. Selection of ' $\mathrm{GV}$ ' grid boxes was random and hence each kriging realization was 279 repeated 10 times in a Monte Carlo (MC) fashion to derive an average scenario. The semi280 variogram and correlation lengths were computed on the basis of the $50 \%$ of the assumed 281 'available' data. Spatial correlograms for each uncertainty metric were derived and the 282 correlation length (CL), where the autocorrelation dropped to 1/e (e-folding distance), was 283 computed. The empirical semi-variograms were derived and then idealized as exponential semi284 variogram functions.

285 Tang and Hossain (2009) showed that the transfer of uncertainty metrics using kriging 286 did not lead to wholesale changes in the pattern of the uncertainty field when compared to the 287 true climatologic uncertainty field (see upper left and upper right panels of Figure 4a). Overall, 288 their assessment indicated that 'transfer' uncertainty metrics from a gauged to an ungauged 289 location through spatial interpolation has merit for selected uncertainty metrics. In Figure $4 \mathrm{~b}$, the 290 histograms for 'kriging error' and actual uncertainty (over ungauged grid boxes) demonstrate the 291 accuracy of the transfer method for FAR. Here, the 'kriging error' refers to the difference 292 between 'kriged uncertainty' and 'actual uncertainty', whereas the 'actual uncertainty' is the 293 'measured uncertainty'. In other words, the 'kriging error' is the estimation uncertainty while the 294 'actual uncertainty' is the true dataset uncertainty. The actual GV-based uncertainty (i.e., FAR in 295 this case) is shown in pink while the black line represents the histogram for kriging error. The 
296 histograms for kriging error are considerably lower, by almost an order of magnitude, compared 297 to the actual GV-based uncertainty and are almost unbiased.

298 However, a point to note is that the work of Tang and Hossain (2009) demonstrated the 299 utility of transfer only at the climatologic time scales with a high degree of GV coverage (50\%).

300 Also, at the climatologic scales, the spatial structure of uncertainty can be expected to be well

301 defined and reasonably homogenous (longer correlation lengths of uncertainty that lead to high 302 accuracy for kriging; see Figure 2). Furthermore, the use of the correlation measure may not 303 necessary reflect the most rigorous assessment of accuracy for the transfer of error metrics. For 304 example, there may be high correlation even with large systematic bias in the 'kriged' error 305 metric at non-GV grid boxes. In this study, we therefore explored the effectiveness of kriging at 306 seasonal (and lower) timescales and modeled how the effectiveness of transfer is impacted by 307 GV data coverage. We also assessed the accuracy of transfer using marginal and non-correlation 308 type measures.

Figure 5 shows how GV coverage (as randomly located grid boxes over a region) impacts

310 the accuracy of kriging-based transfer of uncertainty over the grid boxes lacking GV data for two 311 different time scales (climatologic and seasonal in the left and right panels, respectively). The 312 exercise was performed in a manner similar to Tang and Hossain (2009) over the central United

313 States. The GV coverage was systematically varied from $10 \%$ to $90 \%$ and the effectiveness of 314 kriging of uncertainty metric at locations lacking GV data was assessed using the correlation 315 measure with in-situ (sampled) uncertainty metric. For the seasonal case, the summer months of 316 June-July-August in 2007 over the central US was chosen as an example and one seasonal 317 variogram was modeled. 
The most striking feature of the GV-density study is that the effectiveness of an

319 uncertainty transfer scheme, specifically kriging in this example, worsens considerably at low

$320 \mathrm{GV}$ coverage (correlation dropping to under 0.7) as time scales shorten. Qualitatively, this result

321 is expected, and clearly indicates that if a transfer scheme for estimating uncertainty metrics is

322 finer than seasonal scale (ranging from 3-6 hourly to weekly-monthly), the effectiveness for

323 uncertainty transfer would intuitively worsen further with kriging. A similar assessment can be

324 made from Figure 3 on the potential of kriging using dynamically located a sun-asynchronous

325 PMW scans (such as TMI) as proxy-GV data. At 3-6 hours, the probability of a grid box being

326 scanned by a sun-asynchronous TMI ranges from 0.1 to 0.4 . In other words, this is equivalent to

327 a large region having a fixed GV coverage of 10-40\%. Naturally therefore, the effectiveness of

328 OK over the tropics using proxy-GV data in the GPM era may probably not be any better at

329 timescales shorter than a day.

330 In order to demonstrate a more rigorous level of accuracy of the interpolation scheme

331 beyond the correlation measure, we reviewed our kriging simulations for two more scenarios: 1)

332 transfer of uncertainty metric at monthly time scales and 2) transfer of uncertainty metric at

333 weekly time scales. For each scenario, we performed a more in-depth assessment for the months

334 of summer and weeks of June of 2007. We used mean error, in place of correlation measure, to

335 assess the accuracy of the transfer, using the following error definitions:

337 Error $=($ Interpolated Uncertainty Metric - Actual Uncertainty Metric $) /$ Actual Uncertainty Metric

339 Mean Error= Mean of Error (as defined above in Eqn 4) over non-GV grid boxes

340 Std. Dev of Error = Standard Deviation of Error (as defined above) over non-GV grid boxes (6) 
Tables $1 \mathrm{a}$ and $1 \mathrm{~b}$ summarize the assessment of $\mathrm{OK}$ method using mean relative error

342 (Eqn 5) as the main assessment metric for transfer of uncertainty metrics - BIAS, RMSE, POD

343 and FAR. For each uncertainty metric both mean and standard deviation of error of transfer is

344 shown as measures of accuracy and precision, respectively. It is observed that, unlike correlation

345 measure, the mean and standard deviation of error reveal a somewhat different picture on the

346 utility of OK method. The error metric BIAS has the lowest accuracy ranging from $50 \%$ error (at

$34710 \%$ missing GV gridboxes) to $100 \%$ error (at $90 \%$ missing GV gridboxes) for monthly time

348 scale. For weekly timescale, the mean error ranges from $80 \%$ (at $10 \%$ missing GV grid boxes) to

$349120 \%$ (at $90 \%$ missing GV grid boxes). On the other hand, POD, followed by RMSE and FAR,

350 have the highest accuracy for transfer of error metrics at both timescales according the mean

351 relative error measure. As expected, the precision of the kriging based transfer scheme degrades

352 at shorter timescales. At very low GV coverage $(<20 \%)$ the standard deviation of transfer error is

353 high $(>100 \%)$, indicating poor performance of the OK method regardless of the timescale at

354 which the uncertainty metrics are transferred.

\subsection{CONCLUSION: THE CURRENT OPEN ISSUES ON UNCERTAINTY TRANSFER}

In light of the impact of GV coverage and the timescale on effectiveness of uncertainty

358 transfer, we now need to consider the following: 1) explore other techniques for transfer that are

359 more sophisticated than ordinary kriging; and 2) understand how we can leverage the

360 methodological error estimate that is routinely available from uncertainty models such as

361 Huffman (1997) and Kalman filtering techniques that many satellite rainfall data algorithms use

362 (such as, Ushio et al. 2009). In our interpolation method, the spatial structure of rainfall has not

363 been used alongside that of estimation uncertainty. Because the two (rainfall and its estimation 
uncertainty) are related, it may be worthwhile to pursue co-kriging type conditional interpolation

365 schemes that leverage existing information on the satellite rainfall distribution as an extra 366 constraint.

367 Also, for spatial interpolation methods, we should keep in mind that traditional 368 geostatistical tools are pattern filling methods based on the spatial correlation exhibited by two 369 points in space separated by a lag $h$. The variogram computed using this two-point geostatistical 370 approach may simplify the spatial patterns manifested by the complex precipitation systems and 371 surface emissivities that dictate the accuracy of satellite rainfall products at hydrologic time 372 scales over land. For the case of spatial interpolation of ground water contamination, it has 373 recently been demonstrated that the use of a highly non-linear pattern learning technique in the 374 form of an artificial neural network (ANN) can yield significantly superior results under the 375 same set of constraints when compared to ordinary kriging method (Chowdhury et al., 2009). 376 Thus, the use of non-linear mapping techniques are worth an investigation.

Another aspect to keep in mind is the nature of use of each uncertainty metrics. Different 378 users will have naturally different needs. Hydrologist users engaged in flash flood or monsoonal 379 flood forecasting will probably be more interested in the POD $_{\text {RAIN }}$ (to understand the accuracy in 380 estimating peak flow), FAR (to minimize false alarms in flood warnings), and BIAS (to 381 minimize under/over estimation in river stage) for each grid box (see Harris and Hossain, 2008 382 and Hossain and Anagnostou, 2004). Hydrologists engaged in continuous simulation based on 383 soil moisture accounting for drought monitoring and water management would probably focus 384 more on POD NORAIN (to minimize uncertainty in underestimating the soil wetness and 385 evapotranspiration) for each grid box. On the other hand, crop yield and famine forecasters 386 would like to focus more on the seasonal bias over a large agricultural zone during the growing 
387 season as the important indicator of reliability of a satellite rainfall product (personal 388 communication with Dr. Chris Funk of University of California Santa Barbara).

389 In summary, developing an uncertainty transfer scheme that is amenable to operational 390 implementation for estimation of uncertainty metrics for satellite rainfall data over regions 391 lacking surface GV data is a necessary requirement for current and future satellite precipitation 392 missions to advance their hydrologic potential. Hydrologist users around the world need to have 393 a clear understanding of the pros and cons of applying satellite rainfall data for terrestrial 394 hydrologic applications at a given scale if the benefit of these missions is to be maximized. One 395 way of facilitating the understanding is through the routine provision of various measures of 396 uncertainty that are of hydrologic relevance. If this uncertainty information is provided alongside 397 the global and more frequent precipitation observational capability planned in GPM, it will 398 permit us to refine knowledge from physical and hydrologic models that can then be converted to 399 local and global strategies for water resources management. Work is currently undergoing to 400 address some of the open issues discussed above and we hope to report them in the near future.

402 Acknowledgement: The first author (Tang) was supported by the NASA Earth System Science 403 Fellowship (2008-2011). The second author (Hossain) was supported by the NASA New 404 Investigator Program Award (NNX08AR32G). 
411 estimates:

412

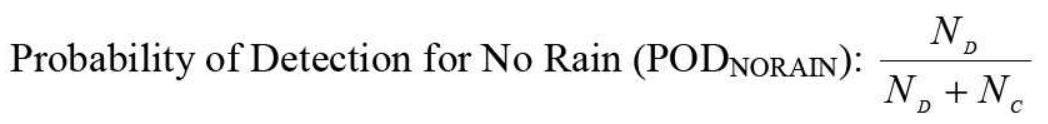

$418 \quad$ False Alarm Ratio (FAR): $\frac{N_{B}}{N_{B}+N_{A}}$

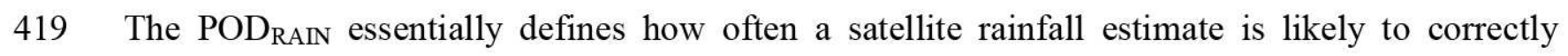
420 detect gridboxes as rainy according to the reference or ground validation data. Similarly, 421 POD $_{\text {NORAIN }}$ defines how often a satellite rainfall estimate is likely to correctly detect a non-rainy 422 grid box as non-rainy according to the ground validation data.

423 


\section{REFERENCES}

425 Anagnostou, E.N. 2004: Overview of overland satellite rainfall estimation for hydro426 meteorological applications. Surveys in Geophysics, 25(5-6), pp. 511-537.

427 Bindlish, R., A.P. Barros. 2000: Disaggregation of rainfall for one-way coupling of atmospheric 428 and hydrological models in regions of complex terrain. Global and Planetary Change, 25, 429 pp. 111-132.

430 Ciach, G.J. and W.F. Krajewski. 1999: Radar-rain gauge comparisons under observational

432 Chowdhury, M., A. Alouani, and F. Hossain. 2009: How much does inclusion of Non-linearity 433 affect the Spatial Mapping of Complex Patterns of Groundwater Contamination? Non-Linear $434 \quad$ Processes in Geophysics, 16, 313-317

435 Forman, B., E. Vivoni, and S. Margulis. 2008: Evaluation of Ensemble-based Distributed 436 Hydrologic Model Response with Disaggregated Precipitation Products, Water Resources Research, 44, W12409, doi:10.1029/2008WR006827.

Fulton, R.A., J.P. Breidenbach, D.-J. Seo, D.A. Miller, and T. O'Bannon, T. 1998: The WSR88D rainfall algorithm. Weather and Forecasting, 13(2), 377-395.

Gebremichael, M., W.F. Krajewski, M. Morrissey, D. Langerud, G. J. Huffman and R. Adler. 2003: Uncertainty uncertainty analysis of GPCP monthly rainfall products: A data based simulation study. Journal of Applied Meteorology, 42(12), 1837-1848.

443 Gebremichael, M., E.N. Anagnostou and M. Bitew. (2010) Critical Steps for Continuing 444 Advancement of Satellite Rainfall Applications for Surface Hydrology in the Nile River 445 Basin, Journal of the American Water Resources Association, (doi: 10.1111/j.1752$446 \quad 1688.2010 .00428 . x)$ 
447 Habib, E., G.J. Ciach, and W.F. Krajewski. 2004: A method for filtering out rain gauge 448 representativeness uncertainty from the verification distributions of radar and raingauge 449 rainfall. Advances in Water Resources, 27(10), 967-980.

450 Harris, A. and F. Hossain. 2008: Investigating Optimal Configuration of Conceptual Hydrologic 451 Models for Satellite Rainfall-based Flood Prediction for a Small Watershed, IEEE 452 Geosciences and Remote Sensing Letters, 5(3), July.

453 Hossain, F. and G.J. Huffman. 2008: Investigating uncertainty metrics for satellite rainfall at 454 hydrologically relevant Scales, Journal of Hydrometeorology, 9(3), 563-575.

455 Hossain, F., N. Katiyar, A. Wolf, and Y. Hong. 2007: The Emerging role of satellite rainfall data 456 in improving the hydro-political situation of flood monitoring in the under-developed regions 457 of the world, Natural Hazards (Special Issue). INVITED PAPER, 43, 199-210.

458 Hossain, F., D.P. Lettenmaier. 2006: Flood prediction in the future: recognizing hydrologic 459 issues in anticipation of the global precipitation measurement mission - Opinion Paper. $460 \quad$ Water Resources Research. 44 (doi:10.1029/2006WR005202)

461 Hossain, F., and E.N. Anagnostou. 2004: Assessment of current passive microwave and infra-red 462 based satellite rainfall remote sensing for flood prediction, Journal of Geophysical Research. 463 109(D7), April, D07102. (doi 10.1029/2003JD003986).

464 Hong Y., K. Hsu, H. Moradkhani, and S. Sorooshian 2006: Uncertainty Quantification of 465 Satellite Precipitation Estimation and Monte Carlo Assessment of the Uncertainty 466 Propagation into Hydrologic Response, Water Resources Research, 42, W08421 467 (doi:10.1029/2005WR004398). 
Hou, A., G.S. Jackson, C. Kummerow, C., and C.M. Shepherd. 2008: Global Precipitation Measurement, In Precipitation: Advances in Measurement, Estimation, and Prediction, (eds) Silas Michaelides, pp. 1-39, Springer Publishers.

471 Huffman, G.J., R.F. Adler, D.T. Bolvin, G. Gu, E.J. Nelkin, K.P. Bowman, Y. Hong, E.F. 472 Stocker, and D.B. Wolff. 2007: The TRMM multi-satellite precipitation analysis: Quasi473 global, multi-year, combined sensor precipitation estimates at fine scales, Journal of Hydrometeorology, $\mathbf{8}, 28-55$.

Huffman, G.J. 2005: Hydrological applications of remote sensing: Atmospheric states and fluxes - precipitation (from satellites) (active and passive techniques). In Encyclopedia for Hydrologic Sciences, M.G. Anderson and J. McDonnel (Eds) (ISBN: 978-0-471-49103-3).

Huffman, G.J., R.F. Adler, M.M. Morrissey. and others. 2001: Global precipitation at one-degree daily resolution from multisatellite observations. Journal of Hydrometeorology, 2, 36-50.

Huffman, G.J. 1997: Estimates of root mean square random uncertainty for finite samples of estimated precipitation, Journal of Applied Meteorology, 36, 1191-1201.

Joyce, R.L., J.E. Janowiak, P.A. Arkin, and P. Xie. 2004: CMORPH: A method that produces 483 global precipitation estimates from passive microwave and infrared data at high spatial and 484 temporal resolution. Journal of Hydrometeorology, 5, 487-503.

485 Krajewski, W. F., et al. 2006: A remote sensing observatory for hydrologic sciences: A genesis 486 for scaling to continental hydrology, Water Resources Research, 42, W07301, 487 doi:10.1029/2005WR004435.

488 Krajewski, W. 1987: Cokriging Radar Rainfall and Rain Gage Data, Journal of Geophysical. 489 Research, 92(D8), 9571-9580. 
Lee, K.H and E.N. Anagnostou. 2004: Investigation of the nonlinear hydrologic response to

491 precipitation forcing in physically based land surface modeling. Canadian Journal of Remote $492 \quad$ Sensing, 30, 706-716.

493 Li, Q., R. Ferraro, and N.C. Grody. 1998: Detailed analysis of the uncertainty associated with 494 rainfall retrieved NOAA/NESDIS SSM/I rainfall algorithm: Part I, tropical oceanic rainfall. 495 Journal of Applied Meteorology, 39, 680-685.

496 Lin, Y., and K. Mitchell. 2005: The NCEP Stage II/IV hourly precipitation analyses: 199

497 development and applications. 19th AMS Conference on Hydrology.

498 McCollum, J.R., W.F. Krajewski, R.R. Ferraro, and M.B. Ba. 2002: Evaluation of biases of 499 satellite rainfall estimation algorithms over the continental United States. Journal of Applied $500 \quad$ Meteorology, 41(11), 1065-1080.

501 Rahman, S., A.C. Bagtzoglou, F. Hossain, L. Tang, L.Yarbrough, G. Easson, G. 2009: 502 Investigating Spatial Downscaling of Satellite Rainfall Data for Flood Prediction, Journal of $503 \quad$ Hydrometeorology, doi:10.1175/2009JHM1072.1

504 Seo, D.J., W. Krajewski, and D. Bowles 1990: Stochastic Interpolation of Rainfall Data From 505 Rain Gages and Radar Using Cokriging, 1, Design of Experiments, Water Resources. $506 \quad$ Research, 26(3), 469-477.

507 Su, F., Hong, Y., and D.P. Lettenmaier. 2008: Evaluation of TRMM Multisatellite Precipitation 508 Analysis (TMPA) and Its Utility in Hydrologic Prediction in the La Plata Basin, Journal of $509 \quad$ Hydrometeorology, 9, 622-640.

510 Syed, T.H., V. Lakshmi, E. Paleologos, D. Lohmann, K. Mitchell, J. Famiglietti. 2004: Analysis 511 of process controls in land surface hydrological cycle over the continental United States, 512 Journal of Geophysical Research 109(D22105), (doi: 10.1029/2004JD004640). 
513 Tang, L. and F. Hossain. 2009: Transfer of satellite rainfall uncertainty from gauged to ungauged 514 locations: How realistic will it be for the Global Precipitation Mission? Geophysical $515 \quad$ Research Letters, 36, (doi:10.1029/2009GL037965).

516 Ushio T., K. Sasashige, T. Kubota, S. Shige, K. Okamoto, K. Aonashi, T. Inoue, N. Takahashi, 517 T. Iguchi, M. Kachi, R. Oki, T. Morimoto, Z. Kawasaki, 2009: A Kalman Filter Approach to 518 the Global Satellite Mapping of Precipitation (GSMaP) from Combined Passive Microwave 519 and Infrared Radiometric Data. Journal of the Meteorological Society of Japan, 87, 137-151.

520 Villarini, G., and W.F. Krajewski. 2007: Evaluation of the research-version TMPA three-hourly $521 \quad 0.25^{\circ} \times 0.25^{\circ}$ rainfall estimates over Oklahoma, Geophysical Research Letters, 34(L05402).

522 Voisin, N., A.W. Wood, and D.P. Lettenmaier. 2008: Evaluation of precipitation products for 523 global hydrological prediction. Journal of Hydrometeorology, 9(3), 388-407. 
526

Figure 1. Conceptual rendition of the idea of 'transfer' of uncertainty information from a gaged (GV) location to an ungaged (non-GV) location. Upper panel depicts the notion of 'uncertainty' of satellite rainfall data (in this case, the scalar deviation of magnitudes is termed 'uncertainty' although there are many other types of uncertainty). Lower panel depicts how the known uncertainty (derived from GV sites shown in black in the middle panel) would be 'transferred' to the non-GV (ungaged) sites shown in blue (right most panel). Reprinted from Tang and Hossain, 2009.

Figure 2. Correlation length of uncertainty metrics at climatologic timescales for 3B41RT (upper panel) and 3B42RT (lower panel) shown as a function of season. Note the distance unit is 0.25 degree grid boxes $(\sim 25 \mathrm{~km})$. The vertical bars are shown in order from left to right as 'Bias', 'RMSE', 'POD rain', 'POD no-rain', 'FAR'. (Taken from Tang and Hossain, 2009).

Figure 3. Left panels: probability of a 3B42RT $0.25^{\circ}$ grid box having a PMW scan from either TMI, SSMIs or AMSR for 3 hour (upper), 6 hour (middle), and 24 hour periods (bottom). Right panels: Same as left panels but only for TMI.

Figure 4a. Transfer of Bias of 3B41RT from gauged to ungauged locations. Upper left-most panel shows the true field of uncertainty in bias based on 6 years of data. The lower left-most panel is the randomly selected $50 \%$ of the region for computation of the empirical variogram and correlation length. The lower middle panel shows the other $50 \%$ of the region that was assumed have no GV. Lower right panel shows the estimation of the bias at the non-GV grid boxes using ordinary kriging.

Figure 4b. Histograms of kriging error and actual error for false alarm ratio (FAR) over ungauged gridboxes. Here kriging error (shown in black) is defined as the difference between transferred (or kriged) FAR and the actual FAR derived from GV data. The actual GV-based FAR is shown in pink.

Figure 4b. Histograms of kriging error and actual error for false alarm ratio (FAR) over ungauged gridboxes. Here kriging error (shown in black) is defined as the difference between transferred (or kriged) FAR and the actual FAR derived from GV data. The actual GV-based FAR is shown in pink.

Figure 5. Impact of GV coverage (or sparseness) on the effectiveness of uncertainty metric transfer by ordinary kriging at climatologic scale (upper panel) and seasonal scale (lower panel) for the central US. . Computed with TMPA data collected for a 100 day period (May-August) in 2007-2008. 


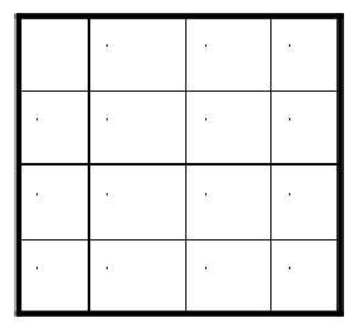

Satellite data

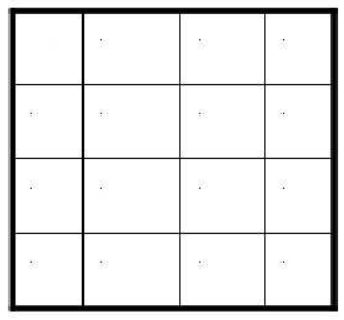

Satellite data

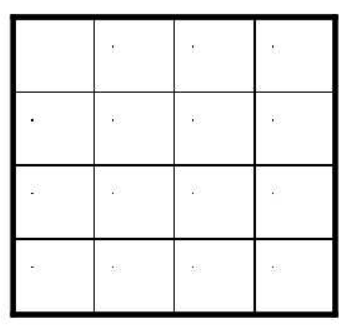

GV data

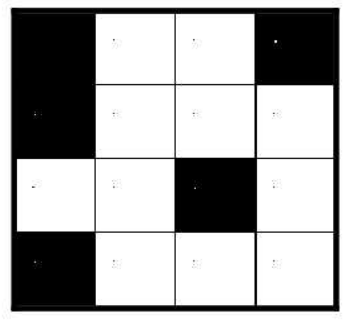

Sparse GV data Gauge or PR Scan

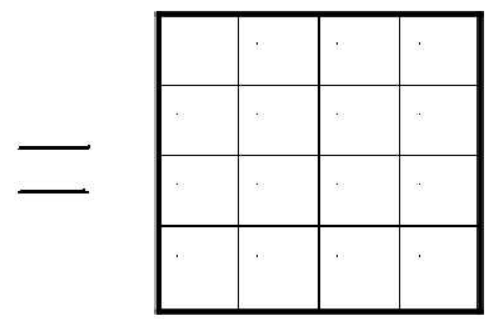

Error

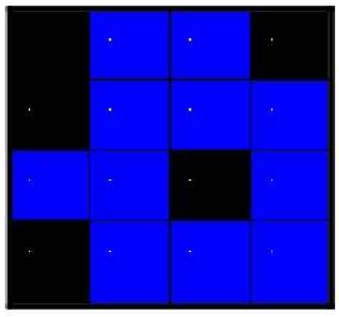

Error

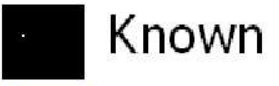

Transferred

Figure 1. Conceptual rendition of the idea of 'transfer' of uncertainty information from a gaged $(\mathrm{GV})$ location to an ungaged (non-GV) location. Upper panel depicts the notion of 'uncertainty' of satellite rainfall data (in this case, the scalar deviation of magnitudes is termed 'uncertainty' although there are many other types of uncertainty). Lower panel depicts how the known uncertainty (derived from GV sites shown in black in the middle panel) would be 'transferred' to the non-GV (ungaged) sites shown in blue (right most panel). Reprinted from Tang and Hossain, 2009. 


\section{B41RT Analysis on Spatial Structure per Season (Correlation Length)}

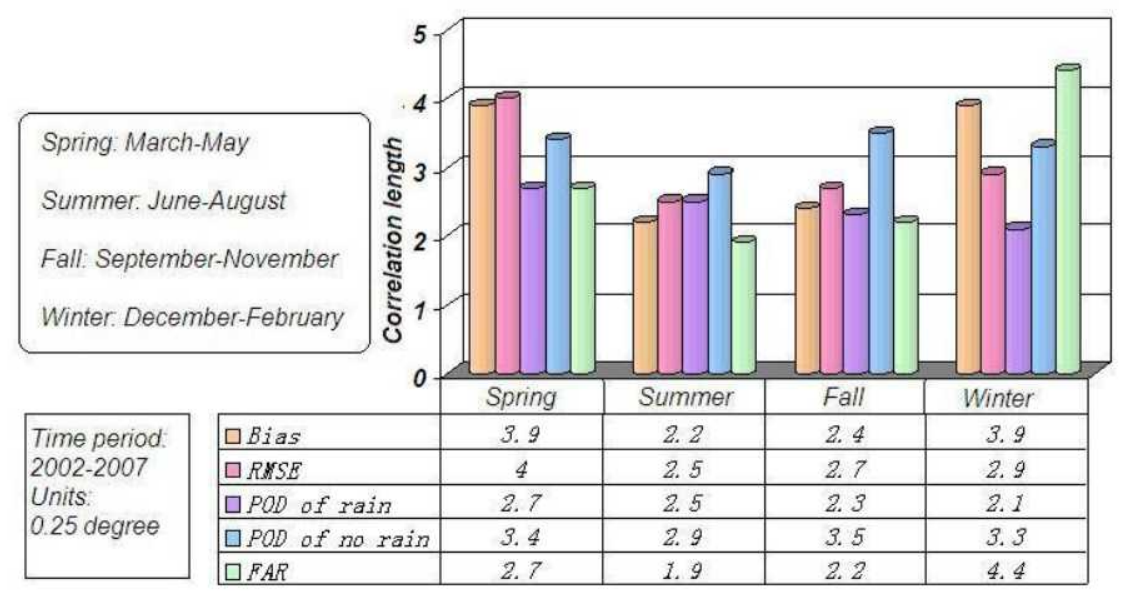

\section{B42RT Analysis on Spatial Structure per Season (Correlation Length)}

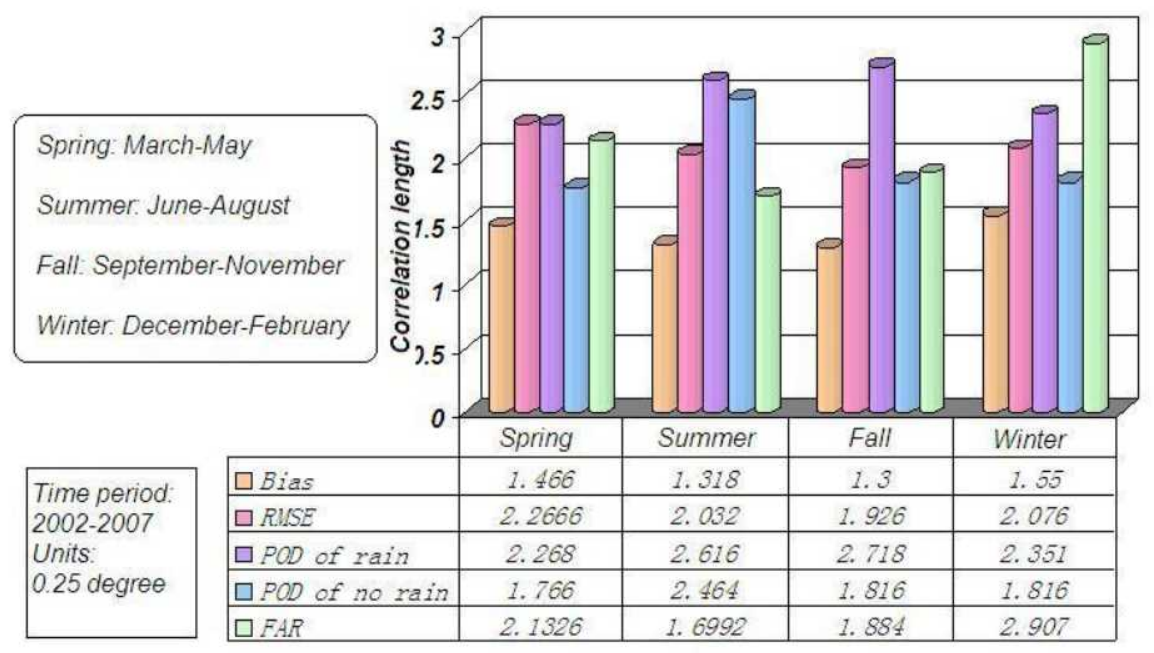

Figure 2. Correlation length of uncertainty metrics for 3B41RT (upper panel) and 3B42RT (lower panel) shown as a function of season. Note the distance unit is 0.25 degree grid boxes $(\sim 25 \mathrm{~km})$. The vertical bars are shown in order from left to right as 'Bias', 'RMSE', 'POD rain', 'POD no-rain', 'FAR'. (Taken from Tang and Hossain, 2009). 


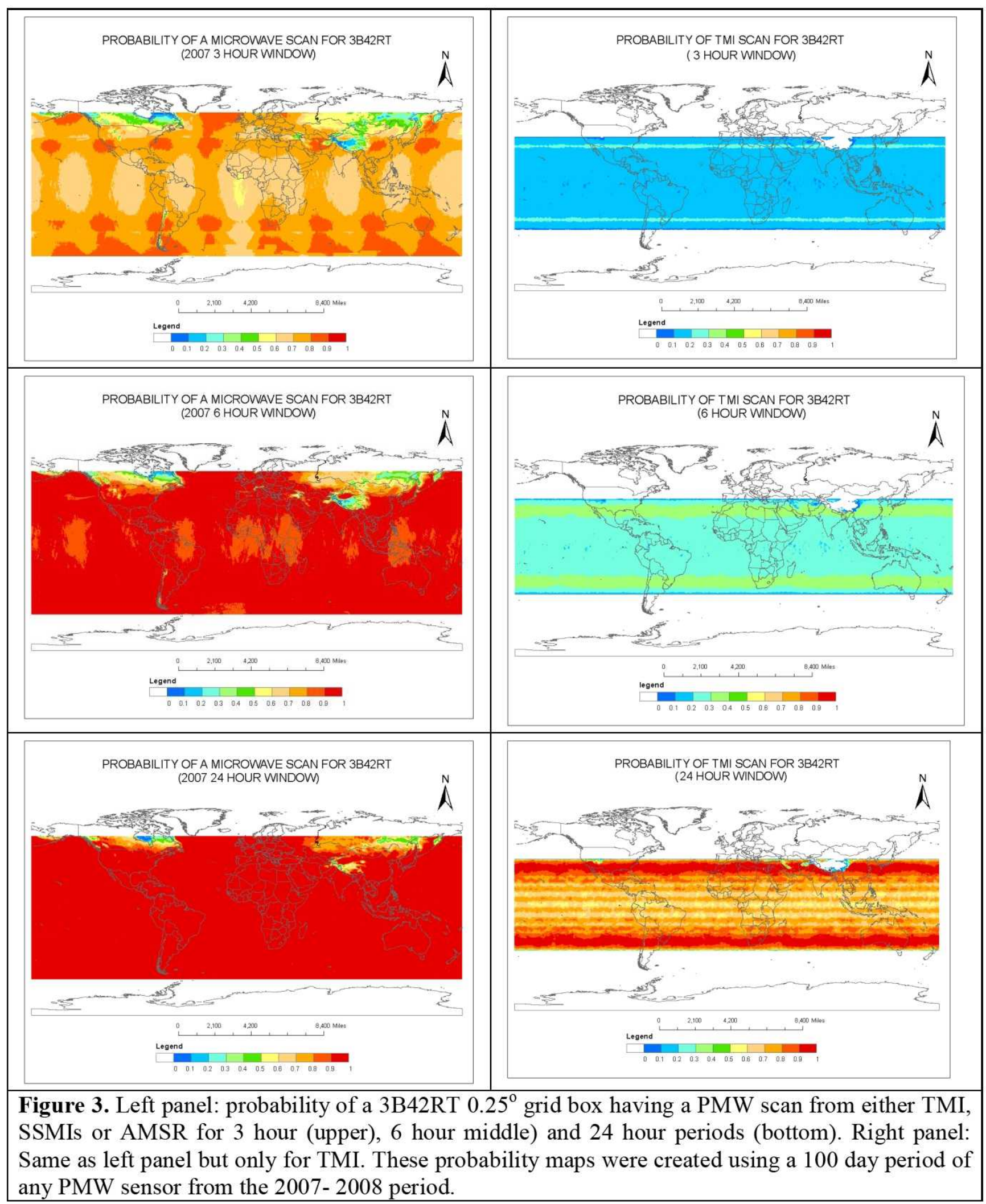




\section{B41RT BIAS}
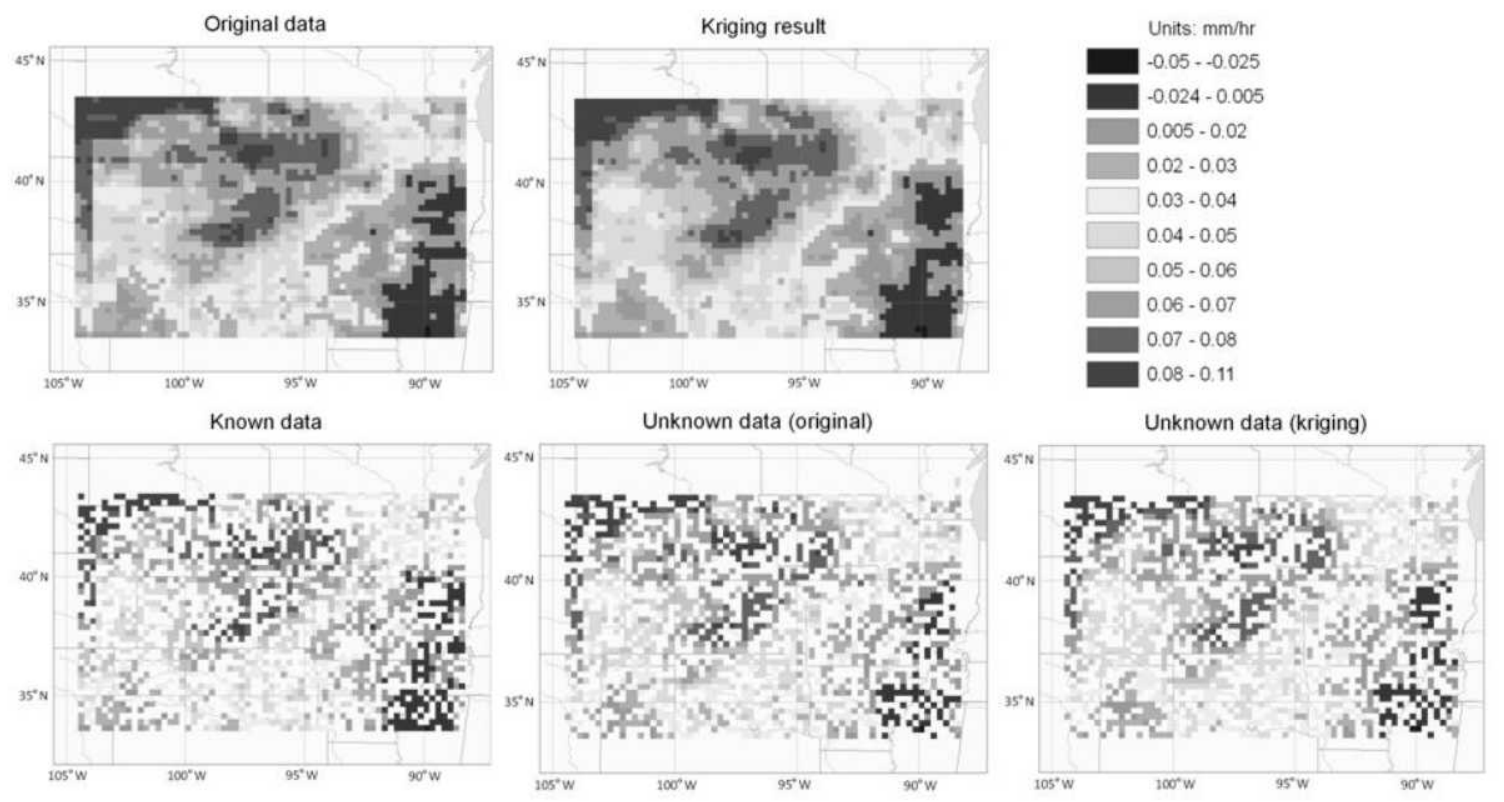

583

584

585

586

587

588

589

590
Figure 4a. Transfer of Bias of 3B41RT from gauged to ungauged locations. Upper leftmost panel shows the true field of uncertainty on bias based on 6 years of data. The lower left most panel is the randomly selected $50 \%$ of the region for computation of the empirical variogram and correlation length. The lower middle panel shows the other $50 \%$ of the region that was assumed to be non-GV grid boxes. Lower right panel shows the estimation of the bias at the non-GV grid boxes using ordinary kriging. 
Figure 4b. Histograms of kriging error and actual uncertainty for false alarm ratio (FAR) over ungauged gridboxes. Here kriging error (shown in black) is defined as the difference between 611

612

613

614 transferred (or kriged) FAR and the actual FAR derived from GV data. The actual GV-based FAR is shown in pink. 

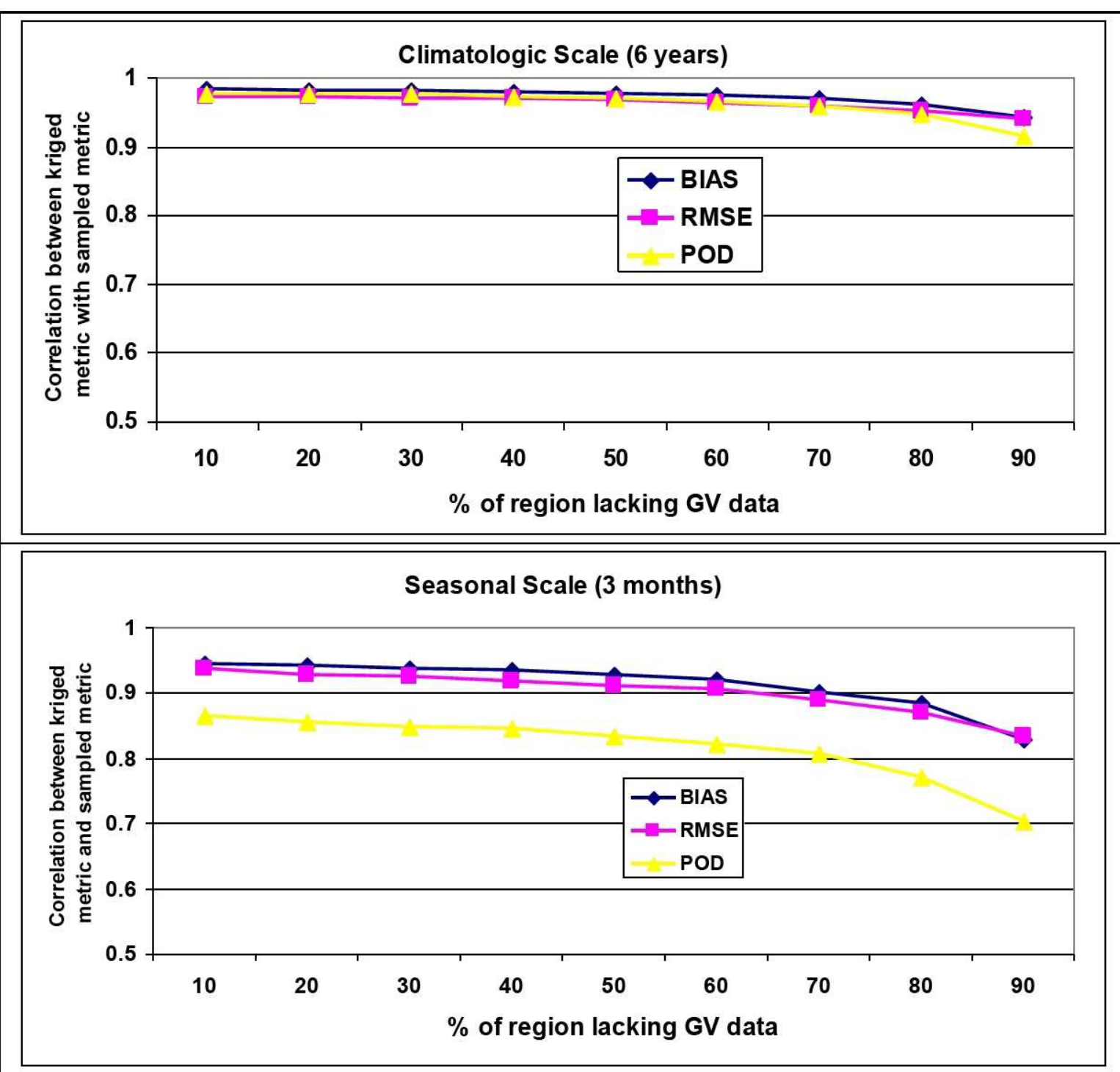

Figure 5. Impact of GV coverage (or sparseness) on the effectiveness of uncertainty metric transfer by ordinary kriging at climatologic scale (upper panel) and seasonal scale (lower panel) for the central US. 
618 Table 1a. Assessment of the transfer of uncertainty metrics at monthly time scales (for summer months of June-July-August).

\begin{tabular}{|c|c|c|c|c|c|c|c|c|c|}
\hline MONTH & $\begin{array}{l}\% \text { of } \\
\text { region } \\
\text { lacking } \\
\mathrm{GV} \\
\text { data }\end{array}$ & BIAS & & RMSE & & POD & & FAR & \\
\hline \multirow[t]{10}{*}{ June } & & $\begin{array}{l}\text { Mean } \\
\text { Error }^{1}\end{array}$ & $\begin{array}{l}\text { Std. } \\
\text { Dev of } \\
\text { Error }^{2}\end{array}$ & $\begin{array}{l}\text { Mean } \\
\text { Error }\end{array}$ & $\begin{array}{l}\text { Std. } \\
\text { Dev } \\
\text { Of } \\
\text { Error }\end{array}$ & $\begin{array}{l}\text { Mean } \\
\text { Error }\end{array}$ & $\begin{array}{l}\text { Std. } \\
\text { Dev of } \\
\text { Error }\end{array}$ & $\begin{array}{l}\text { Mean } \\
\text { Error }\end{array}$ & $\begin{array}{l}\text { Std. } \\
\text { Dev of } \\
\text { Error }\end{array}$ \\
\hline & 10 & 0.53 & 0.78 & 0.19 & 0.18 & 0.12 & 0.10 & 0.22 & 0.27 \\
\hline & 20 & 0.64 & 0.86 & 0.22 & 0.29 & 0.13 & 0.13 & 0.23 & 0.25 \\
\hline & 30 & 0.60 & 0.93 & 0.21 & 0.24 & 0.13 & 0.12 & 0.24 & 0.31 \\
\hline & 40 & 0.66 & 1.00 & 0.22 & 0.24 & 0.13 & 0.14 & 0.22 & 0.26 \\
\hline & 50 & 0.68 & 1.08 & 0.23 & 0.20 & 0.14 & 0.16 & 0.24 & 0.37 \\
\hline & 60 & 0.73 & 1.12 & 0.25 & 0.27 & 0.14 & 0.16 & 0.25 & 0.33 \\
\hline & 70 & 0.75 & 1.11 & 0.26 & 0.25 & 0.15 & 0.15 & 0.26 & 0.35 \\
\hline & 80 & 0.85 & 1.24 & 0.27 & 0.30 & 0.16 & 0.16 & 0.28 & 0.40 \\
\hline & 90 & 1.00 & 1.43 & 0.31 & 0.29 & 0.19 & 0.23 & 0.31 & 0.47 \\
\hline \multirow[t]{10}{*}{ July } & & $\begin{array}{l}\text { Mean } \\
\text { Error }\end{array}$ & $\begin{array}{l}\text { Std. } \\
\text { Dev of } \\
\text { Error }\end{array}$ & $\begin{array}{l}\text { Mean } \\
\text { Error }\end{array}$ & $\begin{array}{l}\text { Std. } \\
\text { Dev } \\
\text { Of } \\
\text { Error }\end{array}$ & $\begin{array}{l}\text { Mean } \\
\text { Error }\end{array}$ & $\begin{array}{l}\text { Std. } \\
\text { Dev of } \\
\text { Error }\end{array}$ & $\begin{array}{l}\text { Mean } \\
\text { Error }\end{array}$ & $\begin{array}{l}\text { Std. } \\
\text { Dev of } \\
\text { Error }\end{array}$ \\
\hline & 10 & 0.54 & 0.71 & 0.20 & 0.20 & 0.16 & 0.15 & 0.32 & 0.43 \\
\hline & 20 & 0.64 & 0.98 & 0.22 & 0.22 & 0.17 & 0.18 & 0.27 & 0.31 \\
\hline & 30 & 0.67 & 0.98 & 0.22 & 0.21 & 0.16 & 0.19 & 0.28 & 0.32 \\
\hline & 40 & 0.61 & 0.85 & 0.23 & 0.24 & 0.18 & 0.22 & 0.31 & 0.41 \\
\hline & 50 & 0.67 & 1.01 & 0.25 & 0.24 & 0.18 & 0.21 & 0.31 & 0.39 \\
\hline & 60 & 0.72 & 1.09 & 0.26 & 0.27 & 0.17 & 0.19 & 0.32 & 0.40 \\
\hline & 70 & 0.80 & 1.13 & 0.26 & 0.24 & 0.19 & 0.24 & 0.33 & 0.44 \\
\hline & 80 & 0.87 & 1.32 & 0.30 & 0.34 & 0.21 & 0.25 & 0.35 & 0.48 \\
\hline & 90 & 0.99 & 1.46 & 0.33 & 0.34 & 0.24 & 0.30 & 0.39 & 0.51 \\
\hline \multirow[t]{10}{*}{ August } & & $\begin{array}{l}\text { Mean } \\
\text { Error }\end{array}$ & $\begin{array}{l}\text { Std. } \\
\text { Dev of } \\
\text { Error }\end{array}$ & $\begin{array}{l}\text { Mean } \\
\text { Error }\end{array}$ & $\begin{array}{l}\text { Std. } \\
\text { Dev } \\
\text { Of } \\
\text { Error }\end{array}$ & $\begin{array}{l}\text { Mean } \\
\text { Error }\end{array}$ & $\begin{array}{l}\text { Std. } \\
\text { Dev of } \\
\text { Error }\end{array}$ & $\begin{array}{l}\text { Mean } \\
\text { Error }\end{array}$ & $\begin{array}{l}\text { Std. } \\
\text { Dev of } \\
\text { Error }\end{array}$ \\
\hline & 10 & 0.47 & 0.79 & 0.21 & 0.22 & 0.14 & 0.17 & 0.28 & 0.47 \\
\hline & 20 & 0.56 & 0.84 & 0.24 & 0.32 & 0.16 & 0.19 & 0.28 & 0.41 \\
\hline & 30 & 0.52 & 0.78 & 0.23 & 0.28 & 0.15 & 0.17 & 0.28 & 0.35 \\
\hline & 40 & 0.62 & 1.00 & 0.24 & 0.30 & 0.15 & 0.17 & 0.27 & 0.34 \\
\hline & 50 & 0.62 & 0.95 & 0.25 & 0.34 & 0.16 & 0.21 & 0.27 & 0.35 \\
\hline & 60 & 0.70 & 1.09 & 0.26 & 0.30 & 0.17 & 0.21 & 0.27 & 0.34 \\
\hline & 70 & 0.69 & 1.05 & 0.30 & 0.36 & 0.17 & 0.20 & 0.29 & 0.40 \\
\hline & 80 & 0.78 & 1.16 & 0.36 & 0.49 & 0.18 & 0.20 & 0.31 & 0.43 \\
\hline & 90 & 0.83 & 1.19 & 0.35 & 0.42 & 0.21 & 0.23 & 0.33 & 0.50 \\
\hline
\end{tabular}


624 Table 1b. Assessment of transfer of uncertainty metric at weekly time scales (for June weeks).

\begin{tabular}{|c|c|c|c|c|c|c|c|c|c|}
\hline $\begin{array}{l}\text { Week } \\
\text { (of } \\
\text { June) }\end{array}$ & $\begin{array}{l}\% \text { of } \\
\text { region } \\
\text { lacking } \\
\text { GV } \\
\text { data }\end{array}$ & \multicolumn{2}{|l|}{ BIAS } & \multicolumn{2}{|l|}{ RMSE } & \multicolumn{2}{|l|}{ POD } & \multicolumn{2}{|l|}{ FAR } \\
\hline \multirow[t]{10}{*}{$\begin{array}{l}1^{\text {st }} \\
\text { Week }\end{array}$} & & $\begin{array}{l}\text { Mean } \\
\text { Error }^{1}\end{array}$ & $\begin{array}{l}\text { Std. } \\
\text { Dev of } \\
\text { Error }^{2}\end{array}$ & $\begin{array}{l}\text { Mean } \\
\text { Error }\end{array}$ & $\begin{array}{l}\text { Std. } \\
\text { Dev } \\
\text { Of } \\
\text { Error }\end{array}$ & $\begin{array}{l}\text { Mean } \\
\text { Error }\end{array}$ & $\begin{array}{l}\text { Std. } \\
\text { Dev of } \\
\text { Error }\end{array}$ & $\begin{array}{l}\text { Mean } \\
\text { Error }\end{array}$ & $\begin{array}{l}\text { Std. } \\
\text { Dev of } \\
\text { Error }\end{array}$ \\
\hline & 10 & 0.78 & 1.13 & 0.45 & 0.73 & 0.27 & 0.29 & 0.35 & 0.32 \\
\hline & 20 & 0.88 & 1.17 & 0.46 & 0.68 & 0.28 & 0.29 & 0.35 & 0.32 \\
\hline & 30 & 0.87 & 1.16 & 0.41 & 0.53 & 0.31 & 0.34 & 0.36 & 0.33 \\
\hline & 40 & 0.86 & 1.15 & 0.48 & 0.76 & 0.33 & 0.35 & 0.35 & 0.31 \\
\hline & 50 & 0.97 & 1.25 & 0.41 & 0.54 & 0.33 & 0.35 & 0.34 & 0.30 \\
\hline & 60 & 0.93 & 1.15 & 0.53 & 0.83 & 0.33 & 0.36 & 0.38 & 0.34 \\
\hline & 70 & 1.05 & 1.35 & 0.52 & 0.80 & 0.34 & 0.36 & 0.38 & 0.32 \\
\hline & 80 & 0.98 & 1.15 & 0.56 & 0.81 & 0.37 & 0.38 & 0.38 & 0.33 \\
\hline & 90 & 1.15 & 1.37 & 0.74 & 1.06 & 0.39 & 0.38 & 0.40 & 0.38 \\
\hline \multirow[t]{10}{*}{$\begin{array}{l}2^{\text {nd }} \\
\text { Week }\end{array}$} & & $\begin{array}{l}\text { Mean } \\
\text { Error }\end{array}$ & $\begin{array}{l}\text { Std. } \\
\text { Dev of } \\
\text { Error }\end{array}$ & $\begin{array}{l}\text { Mean } \\
\text { Error }\end{array}$ & $\begin{array}{l}\text { Std. } \\
\text { Dev } \\
\text { Of } \\
\text { Error }\end{array}$ & $\begin{array}{l}\text { Mean } \\
\text { Error }\end{array}$ & $\begin{array}{l}\text { Std. } \\
\text { Dev of } \\
\text { Error }\end{array}$ & $\begin{array}{l}\text { Mean } \\
\text { Error }\end{array}$ & $\begin{array}{l}\text { Std. } \\
\text { Dev of } \\
\text { Error }\end{array}$ \\
\hline & 10 & 0.85 & 1.23 & 0.39 & 0.77 & 0.23 & 0.25 & 0.35 & 0.31 \\
\hline & 20 & 0.81 & 1.15 & 0.37 & 0.64 & 0.25 & 0.27 & 0.34 & 0.32 \\
\hline & 30 & 0.82 & 1.20 & 0.47 & 0.78 & 0.26 & 0.29 & 0.37 & 0.37 \\
\hline & 40 & 0.80 & 1.19 & 0.47 & 0.77 & 0.27 & 0.31 & 0.37 & 0.37 \\
\hline & 50 & 0.90 & 1.33 & 0.47 & 0.75 & 0.26 & 0.27 & 0.35 & 0.33 \\
\hline & 60 & 0.94 & 1.28 & 0.48 & 0.78 & 0.28 & 0.31 & 0.36 & 0.32 \\
\hline & 70 & 0.94 & 1.29 & 0.51 & 0.84 & 0.29 & 0.32 & 0.38 & 0.36 \\
\hline & 80 & 1.08 & 1.45 & 0.61 & 0.96 & 0.29 & 0.33 & 0.38 & 0.38 \\
\hline & 90 & 1.11 & 1.46 & 0.68 & 1.06 & 0.31 & 0.38 & 0.40 & 0.37 \\
\hline \multirow[t]{10}{*}{$\begin{array}{l}3^{\text {rd }} \\
\text { Week }\end{array}$} & & $\begin{array}{l}\text { Mean } \\
\text { Error }\end{array}$ & $\begin{array}{l}\text { Std. } \\
\text { Dev of } \\
\text { Error }\end{array}$ & $\begin{array}{l}\text { Mean } \\
\text { Error }\end{array}$ & $\begin{array}{l}\text { Std. } \\
\text { Dev } \\
\text { Of } \\
\text { Error }\end{array}$ & $\begin{array}{l}\text { Mean } \\
\text { Error }\end{array}$ & $\begin{array}{l}\text { Std. } \\
\text { Dev of } \\
\text { Error }\end{array}$ & $\begin{array}{l}\text { Mean } \\
\text { Error }\end{array}$ & $\begin{array}{l}\text { Std. } \\
\text { Dev of } \\
\text { Error }\end{array}$ \\
\hline & 10 & 0.76 & 1.04 & 0.42 & 0.56 & 0.28 & 0.33 & 0.31 & 0.28 \\
\hline & 20 & 0.80 & 1.25 & 0.50 & 0.77 & 0.28 & 0.29 & 0.32 & 0.29 \\
\hline & 30 & 0.79 & 1.25 & 0.54 & 0.91 & 0.31 & 0.34 & 0.33 & 0.30 \\
\hline & 40 & 0.82 & 1.19 & 0.52 & 0.80 & 0.32 & 0.37 & 0.32 & 0.29 \\
\hline & 50 & 0.83 & 1.18 & 0.55 & 0.93 & 0.31 & 0.33 & 0.32 & 0.32 \\
\hline & 60 & 0.86 & 1.26 & 0.52 & 0.75 & 0.32 & 0.36 & 0.33 & 0.32 \\
\hline & 70 & 0.94 & 1.32 & 0.58 & 0.90 & 0.32 & 0.34 & 0.33 & 0.33 \\
\hline & 80 & 0.98 & 1.30 & 0.60 & 0.88 & 0.35 & 0.38 & 0.34 & 0.35 \\
\hline & 90 & 1.09 & 1.43 & 0.73 & 1.16 & 0.39 & 0.44 & 0.39 & 0.38 \\
\hline
\end{tabular}


629 Table A.1. Contingency Table (a HIT is defined when both satellite and GV agree on the type of 630 event detected; a MISS is when there is disagreement between satellite and GV detected events).

631

632

633

Truth/Reference

634

635

636

637

638

639

640

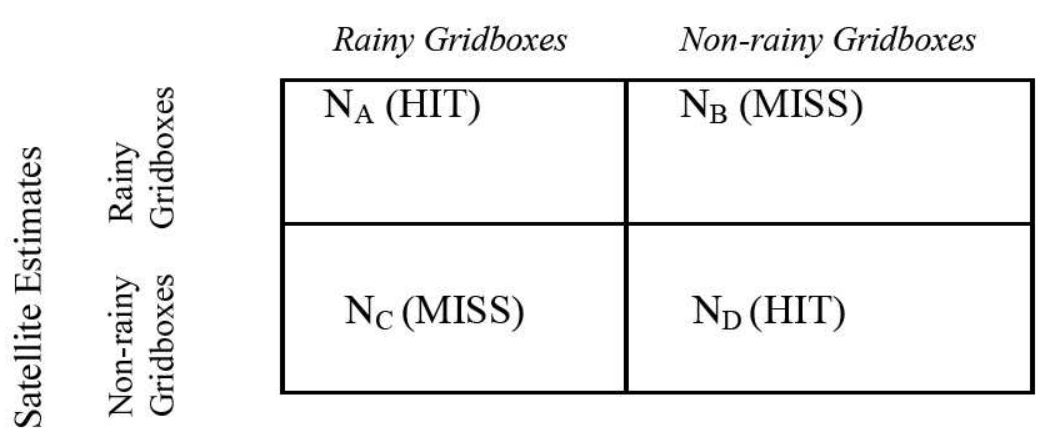

641 